elegance added would convey an idea of what the animal was doing.

I submit that the error which leads the experimenters so far is forgetting that the mechanism of the human eye has as much to do with the matter as the movements of the horse's feet.

Confining my argument to the gallop, I contend that the conventional extended attitude is true artistically, though it never actually takes place whilst the loorse is at this pace. The eye (as is sufficiently proved by the need of machinery for finding out the actual motions of horses' feet) does not obliterate and receive impressions sufficiently quickly to trace the three paces in the gallop; but it can note the fact that at some moment during each bound, each of the four reach this extreme point. Now the feet are twice as long at this point as at any other, that is to say, the passing out over and returning along the last inch is for the eye a pause at the extreme. It is no more doubtful

\section{A Curious Rainbow}

I sEND you a rough sketch of a curious rainbow group seen in Gareloch about 8.25 A.M. on October 20 . I would have written sooner but I delayed till I had obtained sketches from several different sources. I only saw the junction of the two bows at $\mathrm{C}$, that a galloping horse should be painted as it usually is, than that a swinging pendulum can only be suggested by drawing it at one or other extreme of its excursion. An artist could no more use Prof. Marey's diagrams in the way it is assumed he should, than he could represent a rolling wheel if he took no liberties with the apparent position of the spokes; but confined himself by remembering their true places and numbers, which of course are the same as when the wheel is at rest.

It is true that a galloping horse might also be represented with all its legs gathered under it, but this is not done, because, as I agree with Prof. Marey, "it is the artist's duty to add elegance of form;" whilst I dissent from him when he allows himself to be convinced that "the greater part of the horses [of Phidias] are represented in false attitudes" because the odograph says so.

Edinburgh, November 12

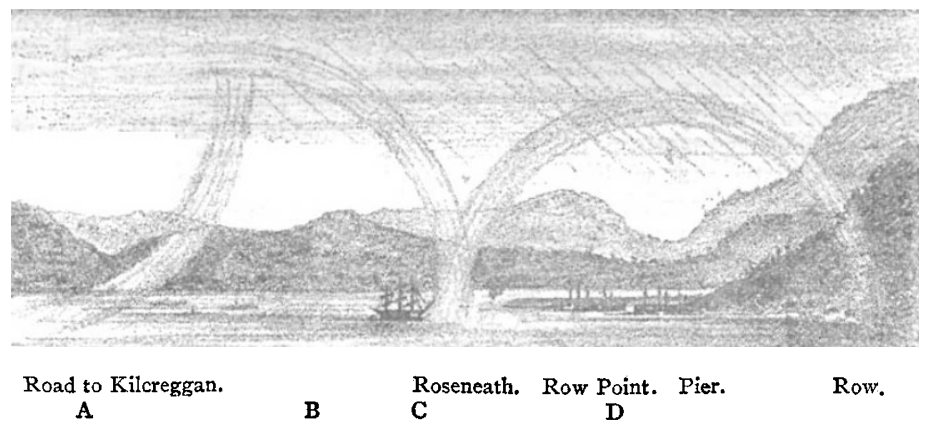

but the bay was quite calm. The bow $D$ was perfectly fall and bright, while B died away at its highest point. I can only imagine that $\mathbf{B}$ was formed by light reflected by some bright cloud, but I did not observe any bright enough. The view is nearly north-west. As I have never even among our Scottish that being the only part of Row Bay visible from my standpoint, but several observers saw the whole group as I have drawn it. The sea was quite glassy, so that the inverted rainbow $\mathrm{A}$ must have been formed by the sun's rays reflected from the water. The wind was just beginning to rise and some scudding showers were passing up from the Firth of Clyde from the south-west,

\section{How Snakes shed the Skin}

IN NATURE, vol. xx. p. 530, Dr. H. F. Hutchinson, amid some interesting facts about snakes, says : "I have never witnessed the process of slin-shedding, nor, I believe, has any observer." The Doctor then ventures an ingenious, though incorrect, hypothesis of his own. In the American Naturalist for January, 1875 , i.e., vol. ix. No. I, under the title, "The Pine Snake of New Jersey," I gave an article embodying the results of several years' study of Pituophis melanoleucus, in which the process of exuviation is described as witnessed by myself. Herewith is an abstract. The few words interpolated for the sake of clearer exposition are put in brackets.

Near the close of September, I873, at I P.M., looking into the box, I saw that the female snake had started the skin from her head. It was a little torn at the snout, and I found that the head and a little of the neck were denuded. The denuding process was going on, but very slowly. Doubtless the chief difficulty was in starting the skin, and I felt sorry that I did not see the start, The neck was very slowly becoming divested of the old cuticle, which, at first glance, had a sort of back-creeping àspect. What surprised me was the fact that there was not the least friction in the process; that is, there was no rubbing against any exterior object. It really did look as if an invisible power was drawing the skin back upon itself. [Looking closely, I caught the secret. There was a systematic alternate swelling of the body at the neck of the skin, thus stretching it, and making a shoulder in front of the neck, each swelling pushing the loosened skin a little backward.] The old skin at this time is very moist and soft, and any swelling of the body stretches and loosens it. So soon as the exuviation has reached the part of the body containing the larger ribs, this doffing of the old suit proceeds more rapidly, and with a singular system. It is done hills seen such a combination of rainbows, I think the description may have some interest for some of your readers. The hill to the right is Knapps Hill, and is 2,000 feet high and three and a half or four miles distant.

Woodbourne House, Helensburgh, November 4 just in this way : Exactly at the place where the skin seems to be moving backward, a pair of ribs expands. This action enlarges or puffs out the body, and by stretching loosens the skin at that place. In this movement both ribs in the pair act at the same time, just as the two blades of the scissors open together. Now comes a second movement of this pair of ribs, in which action the two ribs alternate with each other. One of them-say the one on the right side-is pushed forward and made to slip out of and in front of the constriction made by the swelling, when it immediately works backward, that is, against the neck of the double receding skin. Now the left rib makes a like advance, and in a similar manner presses backward. [Thus for every increment of exuviation, or backward moviement of the inverting skin, three actions occur with rhythmic method; the expanding of one pair of ribs, the intumescence of the body at that spot, and the pushing back of the skin by the alternate action of each rib.] Thus the final action of each pair of ribs is not synchronous, but alternate, and has a notable sameness of movement and result with that of the alternate hitching of each side of the mouth when swallowing a large prey. Indeed, swallowing, with a serpent, is a misnomer, for that laborious hitching is not more a pushing of the prey down the gullet than a drawing of the body over it. The Western man said he always felt better after getting himself round a good beef-steak. With the serpent this is a literal fact; it puts itself outside of its victim. So with that singular costal action it seems to push the skin backward; but this is an illusion, for it actually pushes itself forward, pulling the skin out as itself advances out of the skin, thus with each movement or advance lengthening the inverted cuticle behind; that is, the old hose everts or evolves itself forward, though it appears as if by some occult force to be pulled on itself backward. 